\title{
Engaging the Invisible
}

\author{
Susan Jowsey \\ Auckland University of Technology \\ Auckland \\ sjowsey@aut.ac.nz
}

\author{
Marcus Williams \\ Unitec Institute of Technology \\ Auckland \\ mwilliams@unitec.ac.nz
}

\begin{abstract}
O-Tū-Kapua [what clouds see] is a Mixed Reality art-science project designed to stimulate young learners engagement with scientific concepts. Through complex, multidimensional narratives, this collaborative project has created a blend space where the interaction of Augmented Reality, physical place, analogue making and digital storytelling, are combined in the creation of a situated, embodied learning experience for primary school children.
\end{abstract}

\section{CCS CONCEPTS}

- Applied computing $\rightarrow$ Interactive learning environments; Collaborative learning; Fine arts; Media arts;

\section{KEYWORDS}

Mixed Reality, Art-Science, Place Based Education

\section{ACM Reference Format:}

Susan Jowsey and Marcus Williams. 2017. Engaging the Invisible. In Proceedings of SA'17 Symposium on Education. ACM, New York, NY, USA, Article 4, 3 pages. https://doi.org/10.1145/3134368.3139209

\section{INTRODUCTION}

O-Tū-Kapua is an art-science project first staged in west Auckland, New Zealand, exploring the potential inherent in Mixed Reality [MR] to positively engage young learners with science. While this project is located in the South Pacific, the authors assert that the underlying concepts are broadly applicable. The limited success of the current primary level science curriculum in New Zealand offers a springboard for a conversation which asserts that MR provides an ideal space for creating dynamic learning environments that situate science within the realm of the child rather than in abstract investigation. Positioned in this way, learning has the capacity to be taught 'through' connections with culture and place.[Penetito 2009]

\section{OVERVIEW}

O-Tū-Kapua combines art, science, Mixed Reality and education in the creation of a participatory project for primary school children [5 to 11 years of age], focused on atmospheric science, air and air quality within the context of anthropogenic environmental change. [Nelson et al. 2006] The learning experience begins with hands-on making, for the gallery version of this project the making

Permission to make digital or hard copies of part or all of this work for personal or classroom use is granted without fee provided that copies are not made or distributed for profit or commercial advantage and that copies bear this notice and the full citation on the first page. Copyrights for third-party components of this work must be honored For all other uses, contact the owner/author(s).

SA'17 Symposium on Education, November 27-30, 2017, Bangkok, Thailand

(c) 2017 Copyright held by the owner/author(s).

ACM ISBN 978-1-4503-5409-7/17/11 ..\$15.00

https://doi.org/10.1145/3134368.3139209 workshops were hosted by the education team at Te Uru Waitakere Contemporary Gallery, where O-Tū-Kapua was first staged.

Through making, the participants natural inquisitiveness was roused (in this instance the project drew mixed groups of primary school children from 13 local schools). The pupils, absorbed in learning about the native flora and fauna of their surrounding environment chose a precut cardboard silhouette of a native bird or insect as the basis for creating their individualized artwork. This process of analogue making establishes a personal connection with the forest, as well as stimulating the environmental conversations integral to the digital dimensions of this project. Visitor feedback supplied by the gallery noted, children that attended the workshop with their school then brought their family back at the weekend or after school to show them the exhibition and download the App.

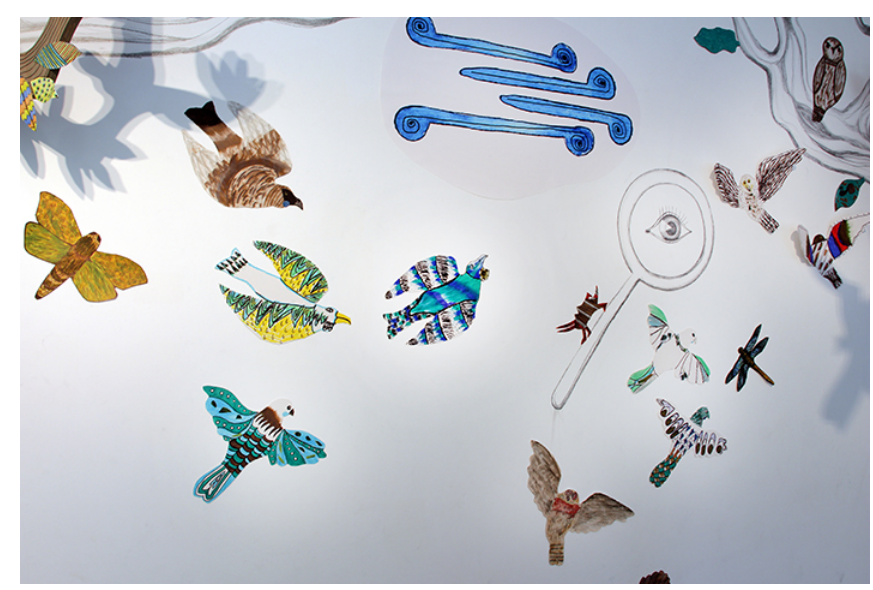

Figure 1: Gallery wall with birds and marker. Image Credit: Te Uru Waitakere Contemporary Gallery

In a gallery, adjacent to the making space, an imaginary forest was constructed from 3D plywood trees that reached to the roof or projected from the walls. [figure 1] When the students had completed their bird or insect artworks they could explore the forest using the O-Tü-Kapua application [App]. Staged like a quest, the pupils hunted for markers amongst the trees using smart devices on which the App was preloaded. Masquerading as drawings of clouds, birds, plants and leaves the markers conjured soundscapes, animations, 360 video of the local Waitakere forest, and a live data visualization. The data visualization is an animated drawing of a tree [figure 3 ] that responds to open-source, real-time air quality and weather data from monitors situated in Auckland, New Zealand's largest city. The health of the tree is indicated by the color of its foliage, humidity is linked to the water level in the middle of its trunk and the traffic density is shown as particles 
surrounding the tree. This visualization links the atmosphere to the health of the immediate environment through a reactive pictorial narrative. The App, soundscapes and animations are also bilingual with texts in Te Reo Māori [Māori language] and English.

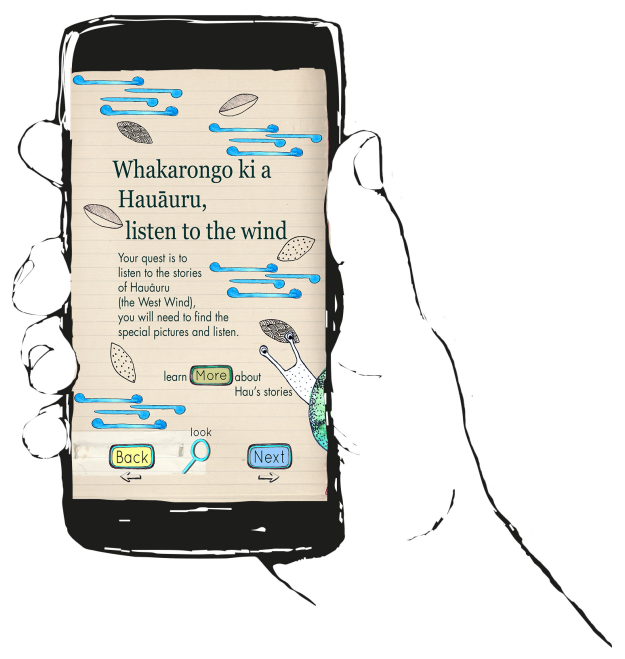

Figure 2: The Wind page from the O-Tu-Kapua App, the design is aesthetically based on a notebook, each element is hand drawn. Image Credit: F4 Collective

\section{EMBEDDED LEARNING}

O-Tū-Kapua was conceived of as a virtual forest, a hand-made world reliant on the creative endeavors of participants [predominantly school children] to fill the forest with life, whilst concomitantly creating an immersive environment for learning. The project incorporates the topic, The Living World, from the national learning framework Level 5 Science Curriculum. The notion of a living world promoted by the framework provided a broad educational basis upon which, the research team could develop a holistic approach to learning about the environment. If children understand the living world as an interdependent ecology, air can be conceptualized as hau [breath], as well as the elemental symbol, O2.

Drawing on culturally derived narratives that combine spiritual, physical and observable notions of interrelatedness, this project explores a range of sensory fields. Employing different forms of augmentation to foster inquiry the project presents knowledge about the world through aural soundscapes and visual cues. Created by Māori composer, Maree Sheehan, the aural narratives permeate the forest installation with the calls of native birds, the patterned sounds of rain, the playful stories of Hauâuru [the West Wind], the darkness of polluted air contrasts with light filled sounds denoting clean air. Born of the Sky Father and Earth Mother, sacred taonga pūoro [traditional Māori musical instruments][Flintoff 2014] call to us. Traditional instruments and their sounds embody physical and spiritual narratives, such as the kōauau [flute] which summons the spiritual world of healing.

The multidimensional nature of this MR project provides a pedagogical framework that supports a questioning engagement with science. The App's MORE buttons link to specific pages on a website that provides scientific information, whilst a print-based handout ensures the content is accessible to all participants. Each element of O-Tū-Kapua was designed to enhance Long Conversations [Mortimer and Scott 2003] (a series of linked questions such as: What happens to our ecosystem if we cut down the trees? Will we still have enough oxygen? Why does the body need oxygen?). Although the MR experience seeks to situate the learning within a local/personal narrative, once students reach the website the conversation expands to include national and global environmental resources. https://www.otukapua.nz

\section{CHALLENGES AND DEVELOPMENTS}

Whilst Te Uru gallery was a convenient site for developing this project and testing its ability to engage learners in situated conversations, practically and educationally it was not ideal, the students making was limited to a two hour workshop which shaped the scope of the learning, but more significantly it required schools to travel off site to participate. Because the learning experience is aesthetically and symbolically located in the world of the child, rather than in its physical site, the research team is currently promoting O-Tū-Kapua's adaptive potential.

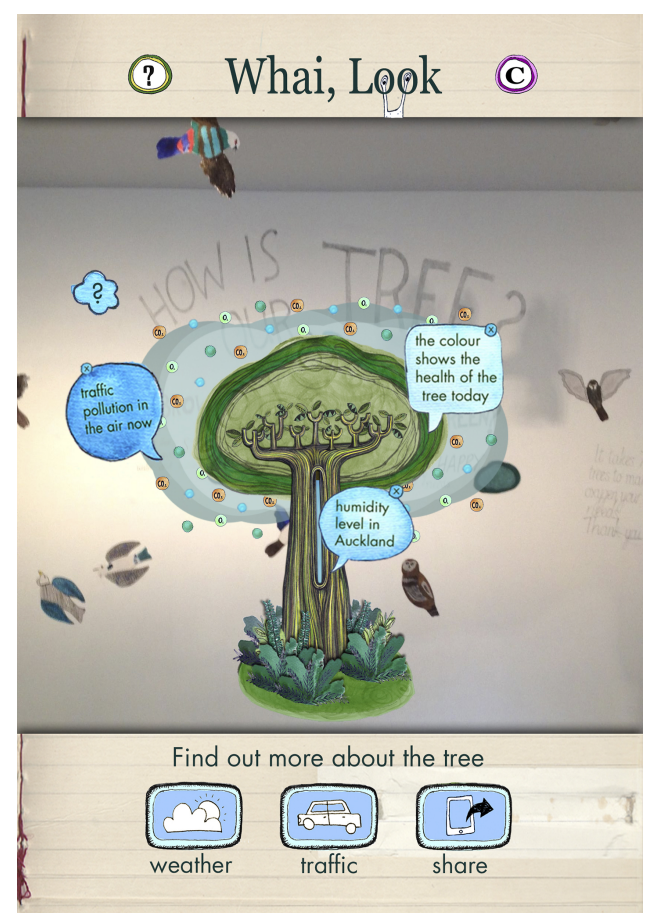

Figure 3: The Augmented Reality page from the O-Tu-Kapua App showing the data responsive tree. The tree is animated, the foliage changes color and the leaves move in response to real time weather data, the level of humidity is indicated by the water level in the middle of the trunk and traffic flow data from Auckland increases or decreases the particles shown in the air around the trees. Image Credit: F4 Collective 
Since its debut, the project has been reconstructed as a whole school experience, all the pupils at Konini School (from 5 to 11 years of age), created birds and insects adding native bats and lizards to the templates, as well as incorporating sculptural making. The teachers constructed a night/day habitat inside a designated classroom, removing all the desks and chairs, before hanging the creative endeavors of over 400 pupils. Each teacher then took their class to visit the environment so that all the pupils could experience the quest and explore the Augmented Reality. As the school was not constrained by the limits of a single two hour workshop the pupils made their artworks over several days, strengthening the class-based discussions about their local habitat. Propitiously this school has an area of native forest within its grounds where pupils carry out, as part of their science curricula, a range of ecological research including pest mapping and plant propagation.

\section{CONCLUSION}

The O-Tū-Kapua project continues to endeavor to introduce scientific concepts into the lived experience of primary school students, using Mixed Reality to place them at the center of the learning experience. Through the creation of a digital legacy, each facet of the project is available for schools, teachers and parents/caregivers to reproduce or reconfigure, or as in the case of Konini School, expand and re-situate it. The projects website houses the templates, instructions, markers, aural and video elements available for download, while the App supplies the quest and Augmented Reality. These component parts can be re-configured in numerous ways, providing the rudiments for developing further educative experiences.

This project attests to the view that indigenous cosmology enhances scientific storytelling, diversifying and enriching scientific method without contradicting it in the mind of a child. Anthropogenic environmental change is a complex issue requiring an expansive relational narrative; connecting place to science conversations promotes exploration of the physical environment as part of oneself, a co-habitor. [Penetito 2009]. Utilizing the potential of Mixed Reality to conjoin divergent/imaginative thinking and pedagogy, this project illustrates how, through generating atypical scenarios that move beyond merely demonstrating scientific concepts, educators can spark inquisitive investigation and catalyze young learners. O-Tū-Kapua evinces the power of MR and the philosophy of Place Based Education as valuable foundations for constructing, through action and curiosity, a space that encourages young people to ask questions and seek knowledge. Promoting the fertile ground created by mixing analogue and digital conversations that enhance scientific stories, engaging the invisible.

\section{ACKNOWLEDGEMENTS}

We wish to acknowledge the researchers involved in this project, Susan Jowsey and Marcus Williams (F4 Artist Collective), The National Institute of Water and Atmospheric Research (NIWA) scientists Gustavo Olivares, Elizabeth Somerville and Guy Coulson. Auckland University of Technology researchers Maree Sheehan, Claudio Aguayo and James Smith, and Roy Davies from IMERSIA. This project received funding from the New Zealand Government through the Ministry of Business, Innovation and Employment (MBIE) Unlocking Curious Minds contestable fund.
To view a short video on the project produced by NIWA. https://vimeo.com/211396969

To read about the project on the MBIE Curious Minds website. http://www.curiousminds.nz/stories/can-art-make-science-a-breath-of-fresh-air/

\section{REFERENCES}

B. Flintoff. 2014. Māori musical instruments - taonga puoro. http://www.TeAra.govt. nz/en/maori-musical-instruments-taonga-puoro. (2014).

Eduardo Mortimer and Philip Scott. 2003. Meaning Making In Secondary Science Classrooms. McGraw-Hill Education (UK).

Gerald C Nelson, A Dobermann, N Nakicenovic, and BC O'Neill. 2006. Anthropogenic drivers of ecosystem change: an overview. Ecology and Society 11, 2 (2006).

Wally Penetito. 2009. Place-based education: Catering for curriculum, culture and community. New Zealand Annual Review of Education 18, 2008 (2009), 5-29. 